The following experiment is typical: A piece of gold is activated with $\operatorname{Th}\left(\mathrm{B}+\mathrm{C}+\mathrm{C}^{\prime}+\mathrm{C}^{\prime \prime}\right)$ by exposure to thoron in the usual way. The gold is immersed in a solution of $\mathrm{Bi}\left(\mathrm{CH}_{3}\right)_{3}$ in ether for two hours. Then a small quantity of the solution is introduced into a small pot inside a Wilson expansion chamber filled with nitrogen. The solution evaporates from the pot, and eventually the $\mathrm{Bi}\left(\mathrm{CH}_{3}\right)_{3}$ settles on the boundaries of the chamber, perhaps oxidised by traces of oxygen. The characteristic $\alpha$-tracks of $\mathrm{Th}\left(\mathrm{C}+\mathrm{C}^{\prime}\right)$ are observed starting from parts of the chamber remote from the pot, thus proving that a volatile compound of ThC has been formed which has evaporated with the rest of the solution. The rate of decay of these $\alpha$-tracks supports the view that the volatile radioactive substance contains ThC and not ThB. A similar effect is found if a source of RaE on nickel is inserted in $\mathrm{Bi}\left(\mathrm{CH}_{3}\right)_{3}$ solution. After a few days the shorter $\alpha$-particles of the subsequent element polonium are found distributed throughout the chamber.

It was necessary to test the hypothesis that the above effects are due to the liberation of 'free methyls' by the break up of heavy molecules under $\alpha$ - and $\beta$-ray bombardment. Such free methyls might pick up atoms from the metallic surface and thus form the volatile radioactive compounds observed. If this mechanism were correct, it must operate for any molecule rich in methyl groups and capable of being broken up. The experiments were therefore repeated, replacing the $\mathrm{Bi}\left(\mathrm{CH}_{3}\right)_{3}$ by $\mathrm{N}\left(\mathrm{CH}_{3}\right)_{3}, \mathrm{Si}\left(\mathrm{CH}_{3}\right)_{4}$ and $\mathrm{Sn}\left(\mathrm{CH}_{3}\right)_{4}$, but in each case the volatile $\alpha$-activity observed was too small to be distinguished definitely from the normal contamination and was certainly of a different order from the effect with $\mathrm{Bi}\left(\mathrm{CH}_{3}\right)_{3}$ and $\mathrm{Pb}\left(\mathrm{CH}_{3}\right)_{4}$. This indicates that the exchange process occurs mainly between atoms of the same atomic number and without the break up of the molecule.

With $\mathrm{Pb}\left(\mathrm{CH}_{3}\right)_{4}$ and $\mathrm{Th}\left(\mathrm{B}+\mathrm{C}+\mathrm{C}^{\prime}+\mathrm{C}^{\prime \prime}\right)$ the effect is remarkable in that the unmistakable $\alpha$ emission of $\operatorname{Th}\left(C+\mathrm{C}^{\prime}\right)$ is observed immediately evaporation begins, and photographs showing these $\alpha$-particles starting in the gas have been obtained. This indicates the unexpected presence of a volatile bismuth compound. On the other hand, the rate of decay of the activity in the chamber is consistent with the ten-hour period of ThB, which must therefore have distilled over with the ThC. This may be explained if the oxidation of $\mathrm{Bi}\left(\mathrm{CH}_{3}\right)_{3}$ is inhibited or retarded in the $\mathrm{Pb}\left(\mathrm{CH}_{3}\right)_{4}$ solution, which will therefore contain equilibrium amounts of $\mathrm{ThC}\left(\mathrm{CH}_{3}\right)_{3}$ and $\mathrm{ThB}\left(\mathrm{CH}_{3}\right)_{4}$ which will evaporate together.

Measurements of the rate of interchange are in progress using an ionisation method and also a tube counter system constructed by Miss E. E. Widdowson, whom we wish to thank, together with Prof. Arthur Ellis, who kindly gave us some old radon tubes.

Alice Leigh-Smith.

King's College, London, W.C.2.

H. O. W. Richardson.

Bedford College, London, N.W.1.

\section{Ebulliometric Determination of the Degree of Decom- position of an Organic Substance}

IN previous papers it has been shown that the application of an ebulliometer with several de. phlegmators ${ }^{1}$ (Fig. 1) filled with an azeotropic mixture of benzene and ethanol or any other binary mixture forming with water a ternary azeotrope, enables one to determine with an accuracy up to 0.001 per cent the quantity of moisture in solid organic substances soluble in the above-mentioned azeotrope. The same method can be applied for determinations of the degree of decomposition of organic substances forming water as one of the products of decomposition.

Let us suppose that the decomposition of succinic acid by heating to the temperature $t$ is examined. For this purpose a certain quantity of this acid is placed in a test-tube which is afterwards closed like a Carius tube. After heating for a certain time at the given temperature, the tube is carefully shaken and the substance is brought to the vessel $A$ of the ebulliometer, which is filled with azeotropic mixture of benzene and ethanol. The water formed by the decom. position of succinic acid forms a ternary system (azeotropic mixture) with benzene and ethanol, which has a lower boiling point than the mixture of benzene and ethanol. Noting the lowering of the condensation temperature in the upper part of the ebulliometer (the thermometer is placed in the uppermost test-tube of the apparatus), it is possible to calculate the quantity of water formed, after carrying out a direct determination of the lower. ing of temperature per milligram of water, introduced into the ebulliometer. The heating of the reflux tubes by microburners must be so regulated that the

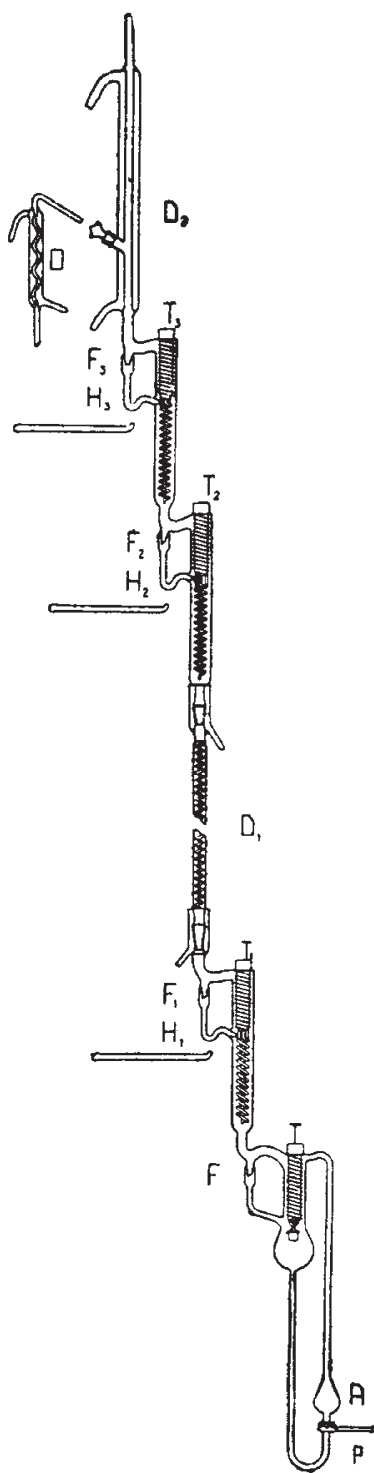

FIG. 1. number of drops flowing through the drop-counters $F, F_{1}, F_{2}, F_{3}$ is approximately the same in both experiments.

The method makes it possible to determine the formation of 0.001 per cent of water by the decom. position of substances. Details will be published elsewhere.

\section{W. SwIETOSrawsKI.}

Institute of Physical Chemistry, Polytechnic High School, Warsaw. 1 W. Swietoslawski, Chemicke listy, 26, 772; 1932 . Conferencias de
Introduccion de IX Congresso International de Quimica Pura Y Aplicada, Madrid, 5-11 April, 1934, p. 9. 